\title{
Real-life Effectiveness and Safety of Amlodipine/Valsartan Single-pill Combination in Patients with Hypertension in Egypt: Results from the EXCITE Study
}

\author{
Samir H. Assaad-Khalil ${ }^{1}$ - Nashwa Nashaat ${ }^{2}$
}

Published online: 8 August 2016

(c) The Author(s) 2016. This article is published with open access at Springerlink.com

\begin{abstract}
Background EXCITE (clinical experience of amlodipine and valsartan in hypertension) evaluated the real-world effectiveness and safety of single-pill combinations (SPCs) of amlodipine/valsartan (Aml/Val) and amlodipine/valsartan/hydrochlorothiazide $(\mathrm{Aml} / \mathrm{Val} / \mathrm{HCTZ})$ in patients with hypertension from the Middle East and Asia.

Objective The objective of this study was to report the results of EXCITE study from Egypt, where all patients were prescribed Aml/Val.

Methods This was a 26-week, observational, multicenter, prospective, non-interventional, open-label study. Effectiveness was assessed as change in the mean sitting systolic/diastolic blood pressure ( $\mathrm{msSBP} / \mathrm{msDBP}$ ) from baseline and the proportion of patients achieving the therapeutic blood pressure (BP) goal $(<140 / 90 ;<130 / 80 \mathrm{mmHg}$ in patients with diabetes mellitus) and $\mathrm{BP}$ response (SBP $<140 \mathrm{mmHg}$ or reduction of $\geq 20 \mathrm{mmHg}$; DBP $<90 \mathrm{mmHg}$ or reduction of $\geq 10 \mathrm{mmHg}$ ). Safety was monitored by recording the incidence of adverse events (AEs) and serious AEs (SAEs).

Results A total of 2566 patients (mean age, 52.6 years; mean duration of hypertension, 7.9 years) were prescribed Aml/Val, of whom 2439 (95.1\%) completed the study. At week 26, Aml/Val SPC significantly $(p<0.0001)$ reduced $\mathrm{msSBP} / \mathrm{msDBP}$ by $-34.5 /-19.4 \mathrm{mmHg}$ from baseline (BP: $164.3 / 100.5 \mathrm{mmHg}$ ). Therapeutic goal, SBP response, and DBP response was achieved by $49.3,91.1$, and $91.4 \%$
\end{abstract}

Samir H. Assaad-Khalil

assaadkhalil@hotmail.com

1 Department of Internal Medicine, Alexandria Faculty of Medicine, 27 Talaat Harb Str./Ramleh Station/Attarin, Alexandria, Egypt

2 Novartis Pharma S.A.E, Cairo, Egypt of patients, respectively. AEs were reported in $12.5 \%$ of patients, with the most common including peripheral edema $(1.8 \%)$, bronchitis $(1.1 \%)$, and gastritis $(0.8 \%)$, and SAEs in $0.5 \%$ of patients. Two deaths were reported during the study, none of which were considered to be study drug related by the investigators.

Conclusion Aml/Val SPC provided clinically significant $\mathrm{BP}$ reductions and was generally well tolerated in patients with hypertension from Egypt.

\section{Key Points}

This real-world study conducted in Egypt showed that a single-pill combination of amlodipine and valsartan was effective in reducing blood pressure and was well tolerated in patients with hypertension.

The present findings related to effectiveness and safety compare well with previously reported real-life studies and are consistent with the findings derived from randomized clinical trials evaluating the amlodipine/ valsartan combination in patients with hypertension.

The diversity of the patient sub-groups (older patients, obese patients, and patients with diabetes mellitus), adds to the clinical implications of the present results.

\section{Introduction}

Hypertension is an important worldwide health challenge, the prevalence of which has been estimated to rise from 972 million people in the year 2000 to 1.56 billion by 2025 
[1]. Of the 1.56 billion people, 1.15 billion will represent the population in economically developing countries, accounting for almost three-fourths of the world's hypertensive population [1]. High blood pressure (BP) is one of the three leading risk factors contributing to global disease burden, especially in most of Asia, most of Latin America, North Africa, the Middle East, and central Europe, accounting for 9.4 million deaths worldwide in 2010 [2].

Hypertension represents a major public health problem in Egypt. The Egypt Demographic and Health Survey (2008) reported the overall prevalence of hypertension as $17.6 \%$, which increased with age. Diabetes mellitus, overweight, and obesity were the leading risk factors associated with the increasing prevalence of hypertension. Although the rate of awareness of hypertension was as high as 54.2 and $43.4 \%$ of patients received treatment, BP control was achieved only by $21.3 \%$, and BP control declined with increasing age $[3,4]$.

Despite the availability of several antihypertensive agents from different pharmacological classes for the management of hypertension, achieving BP control to the recommended target levels is a challenge worldwide [5, 6]. With monotherapy, only $30 \%$ of patients with hypertension are effectively treated, while the majority fails to achieve recommended BP goals [7]. The 2013 European Society of Hypertension/European Society of Cardiology and the 2013 Egyptian Hypertension Society Guidelines recommend two or more antihypertensive medications to be prescribed as combination therapy to achieve BP control in the majority of patients with hypertension [8, 9]. Blockers of the renin-angiotensin-aldosterone system [angiotensin receptor blocker (ARB) or angiotensin-converting enzyme inhibitor (ACEI)] together with a calcium channel blocker (CCB) and/or a diuretic, which have complementary mechanisms of action, are among the recommended combinations of antihypertensive agents [9]. Further, several studies have shown that fixed-dose singlepill combination (SPC) administration has more benefits than the corresponding free combinations of the same drugs, such as improved compliance and persistence to therapy, decreased incidence of adverse effects, and simplification of the therapeutic regimen. As a consequence of improved compliance, overall efficacy and BP control would also be better with SPCs [10].

Amlodipine/valsartan (Aml/Val) and amlodipine/valsartan/ hydrochlorothiazide (Aml/Val/HCTZ) SPCs demonstrated significant and effective BP lowering and were well tolerated in several clinical studies conducted in patients with stage 1 and/or 2 hypertension [11-13]. Reallife observational studies with the Aml/Val combination reported safe and effective reduction of $\mathrm{BP}$ across all hypertension grades as well as in patients with isolated systolic hypertension (ISH), with a majority of the patients attaining BP goals $[14,15]$. Studies conducted in a real-life practice setting provide additional evidence to randomized clinical trials and are of greater relevance to routine clinical practice [16].

The EXCITE (clinical experience of amlodipine and valsartan in hypertension) study was performed in a realworld setting to evaluate the effectiveness and safety of $\mathrm{Aml} / \mathrm{Val}$ and Aml/Val/HCTZ SPCs in patients with hypertension from different developing countries in the Middle East and Asia. Data from each of the above individual countries and the overall pooled data were analyzed to provide a comprehensive overview of the therapies. This article presents the data obtained from patients with hypertension in Egypt and examines if there were any differences in the effectiveness of the Aml/Val SPC at a regional or country level. Such a country-specific analysis provides a closer look into routine clinical practice and can serve as additional evidence to randomized clinical trials.

Additionally, this study presents data derived from specific ethnic populations in the context of hypertension drug therapy, knowing that many therapeutic agents have shown ethnicity-related variations in both efficacy and safety.

\section{Methods}

\subsection{Study Design}

The EXCITE study was an observational, multicenter, multinational, prospective, non-interventional, and openlabel study conducted in patients with hypertension from 13 countries in the Middle East (Bahrain, Egypt, Kuwait, Lebanon, Oman, Qatar, and United Arab Emirates) and Asia (Indonesia, Hong Kong, Pakistan, Philippines, South Korea, and Taiwan). Patients received treatment with either $\mathrm{Aml} / \mathrm{Val}$ or $\mathrm{Aml} / \mathrm{Val} / \mathrm{HCTZ}$ SPCs as part of routine care and according to the local prescribing information in the respective participating countries. Data from one umbrella protocol were pooled for analysis from the countries listed above, including Egypt [17].

In Egypt, all patients with hypertension received the Aml/ Val SPC (dosages $5 / 160$ or $10 / 160 \mathrm{mg}$ ), either as single therapy or add-on therapy to other antihypertensive medications. As the Aml/Val/HCTZ SPC was not registered in Egypt when the study began, only patients receiving the $\mathrm{Aml} / \mathrm{Val}$ SPC were enrolled. The data originating from assessments and evaluations performed according to the physician's routine practice and standard care were collected. The study, along with data collection, commenced in June 2010 and ended in October 2012. There were no additional diagnostic or monitoring procedures beyond usual care. Patient visit intervals were chosen at the physician's discretion and according to usual care. 
The observational period of $26 \pm 8$ weeks included data from at least two routine examinations for each patient at: baseline, week 13 (optional), and study endpoint (week 26 \pm 8 weeks). Demographic and baseline characteristics data of patients including history of hypertension, risk factors, medical history, and use of antihypertensive and other concomitant medications were recorded at study entry.

\subsection{Patients}

Adults (aged $\geq 18$ years) with an established diagnosis of hypertension, for whom SPC treatment with Aml/Val had been prescribed by a treating physician as part of routine patient care, and who consented to data collection, were eligible for inclusion in the study. Patients were excluded from the study if they had any contraindication to Aml/Val as defined in the local prescribing information for their country.

\subsection{Effectiveness Assessments}

Effectiveness was assessed by changes in mean sitting systolic BP (msSBP) and mean sitting diastolic BP (msDBP) from baseline to the end of the study (week $26 \pm$ 8 weeks), and optional data at week 13 were collected. The mean of three sitting BP values were recorded, and BP was measured as per the clinician's practice. The proportion of patients who achieved the therapeutic BP goal $(<140 / 90$; $<130 / 80 \mathrm{mmHg}$ in patients with diabetes) and BP response (SBP $<140 \mathrm{mmHg}$ [130 $\mathrm{mmHg}$ for patients with diabetes] or a reduction of $\geq 20 \mathrm{mmHg}$; DBP $<90 \mathrm{mmHg}$ [80 $\mathrm{mmHg}$ for patients with diabetes] or a reduction of $\geq 10 \mathrm{mmHg}$ ) was also assessed. Subjective assessment of treatment effectiveness was rated by the treating physician as 'below average', 'average', 'good', and 'very good' at the end of the study.

\subsection{Safety Assessments}

Safety assessments included physician monitoring and recording of incidence of all adverse events (AEs), serious adverse events (SAEs), and the incidence of edema. At the end of the study, tolerability and compliance were assessed by the treating physician as 'below average', 'average', 'good', or 'very good, based on a subjective evaluation scale.

\subsection{Statistical Analyses}

All effectiveness and safety analyses were performed on the full analysis set consisting of patients who provided informed consent and entered the study. Analyses were conducted by treatment cohort only or by treatment cohort and treatment dosage, according to the treatment and dosage the patient was taking at the time of entry into the study. Statistical analysis was performed using version 9.2 of the SAS statistical package. The paired $t$ test was used to assess the change in BP from baseline to the end of the study. In the case of patients who discontinued before week 26, the last observation carried forward (i.e., last available post-baseline value) was considered. The data were presented as mean (95\% confidence interval [CI]).

Subgroup analyses were performed for effectiveness variables in the treatment cohort based on diabetic status, baseline SBP $(<140 ; 140$ to $<160 ; 160$ to $<180$ and $\geq 180$ $\mathrm{mmHg}$ ), age ( $<65, \geq 65$ years), sex, ISH at baseline (SBP $\geq 140 \mathrm{mmHg}$ and DBP $<90 \mathrm{mmHg}$ ), and body mass index (BMI) at baseline $\left(<30, \geq 30 \mathrm{~kg} / \mathrm{m}^{2}\right)$.

The incidence of AEs and SAEs was summarized with frequency counts and percentages by preferred term and treatment cohort.

\section{Results}

\subsection{Demographic and Baseline Characteristics}

A total of 2566 patients received the Aml/Val SPC, of whom 2439 (95.1\%) completed the study, 62 (2.4\%) patients prematurely discontinued, and 65 (2.5\%) patients were considered as discontinued, as the study completion page and reason(s) for discontinuation were missing (Fig. 1).

Demographic and baseline characteristics of the patients are presented in Table 1 . The mean age was $52.6( \pm 10.31)$ years and the mean duration of hypertension was 7.9 $( \pm 7.26)$ years, with a baseline sitting BP of 164.4 $( \pm 14.92) / 100.5( \pm 8.63) \mathrm{mmHg}$. Patients in this study reported the following main cardiovascular risk factors: family history of hypertension (39.5\%), dyslipidemia (39.1 $\%$ ), diabetes $(34.4 \%)$, and coronary heart disease $(13.3 \%)$. Prior to study participation, most patients $(78.9 \%)$ were taking antihypertensive agents, with the most frequently used classes of antihypertensive medications being selective beta-blockers $(24.5 \%)$, ACEIs (20.8\%), dihydropyridine derivatives $(15.8 \%)$, and angiotensin II antagonists (10.6\%).

The most common reason for changing previous treatment to receive the $\mathrm{Aml} / \mathrm{Val} \mathrm{SPC}$ was unsatisfactory $\mathrm{BP}$ control with prior treatment as reported by 1898 patients $(74.0 \%)$, followed by insufficient compliance with prior treatment in 566 patients $(22.1 \%)$ and insufficient tolerability of prior treatment in 514 patients $(20.0 \%)$. At baseline, 1742 patients $(67.9 \%)$ were prescribed Aml/Val $5 / 160 \mathrm{mg}$ and 824 patients $(32.1 \%$ ) were prescribed Aml/ Val 10/160 mg. At baseline, week 13, and week 26, 662 
Fig. 1 Patient disposition. $C R F$ case report form

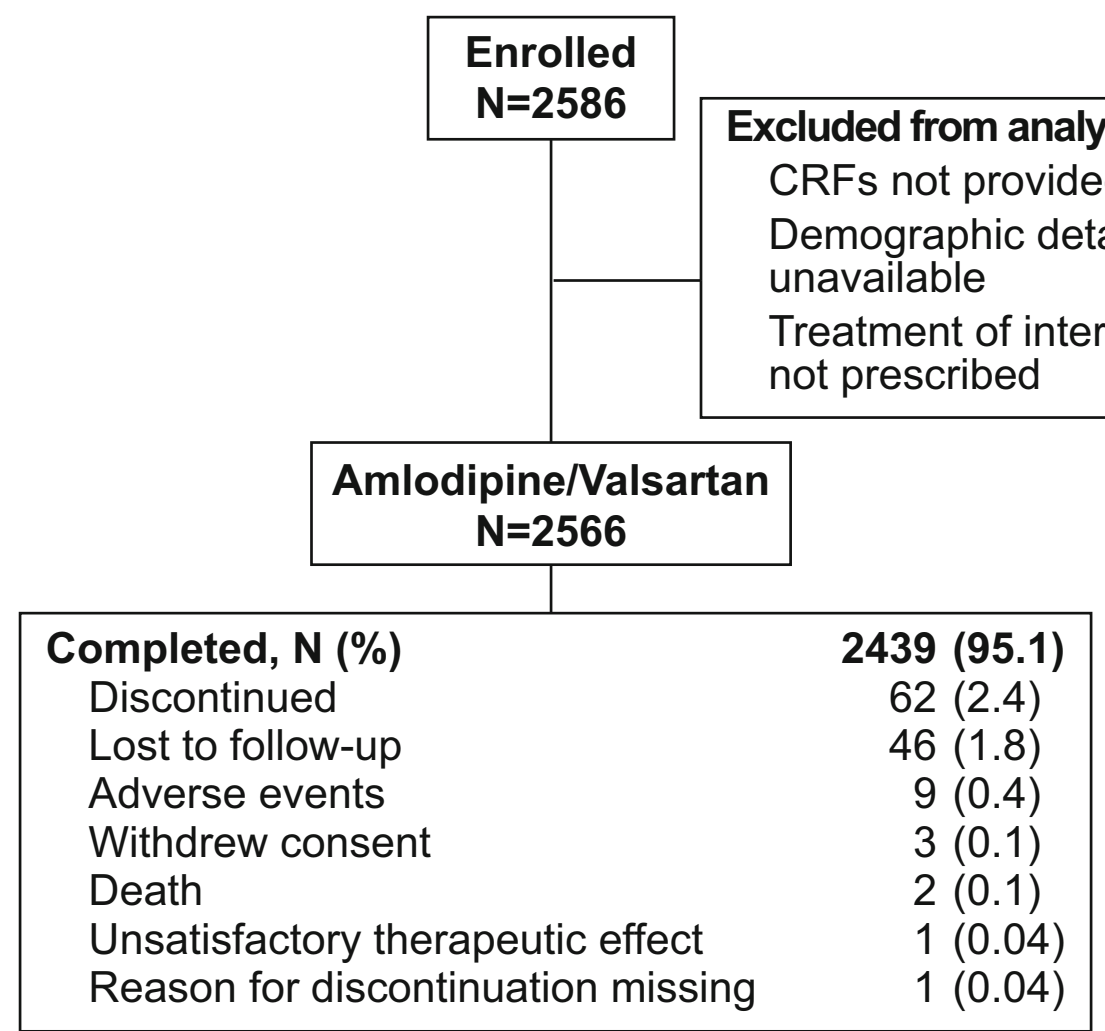

For 2 patients, information about study completion was missing and for 63 patients, the study completion page was missing and therefore, information about completion or reason for discontinuation was not available patients $(25.8 \%), 347$ patients $(13.5 \%)$, and 340 patients $(13.5 \%)$ received concomitant antihypertensive treatment in addition to the study drug. Selective beta-blockers were the most commonly prescribed medication at baseline, week 13, and week 26.

\subsection{Effectiveness}

\subsubsection{Change in BP from Baseline to Endpoint}

At week 13, the mean ( \pm standard deviation) reduction observed in mean sitting BP was $-28.8( \pm 15.81) /-16.1$ $( \pm 9.47) \mathrm{mmHg}$ with the Aml/Val $\mathrm{SPC}$ in the overall population (baseline BP, 165.2/100.9 $\mathrm{mmHg} ; n=2041$ ), $-26.9( \pm 14.83) /-15.5( \pm 9.55) \mathrm{mmHg}$ with $\mathrm{Aml} / \mathrm{Val}$ $5 / 160 \mathrm{mg}$ (baseline BP, $162.8 / 99.9 \mathrm{mmHg} ; n=1390$ ), and $-32.9( \pm 17.03) /-17.4( \pm 9.16) \mathrm{mmHg}$ with $\mathrm{Aml} / \mathrm{Val}$ 10/160 mg (baseline BP, 170.1/102.9 mmHg; $n=651$ ). At the week 26 endpoint, Aml/Val showed clinically significant mean $[95 \%$ CI reductions $(p<0.0001)$ from baseline (baseline BP, 164.3/100.5 $\mathrm{mmHg}$ ) in msSBP $(-34.5$ $\mathrm{mmHg}(95 \% \mathrm{CI}-35.10,-33.85)]$ and msDBP $(-19.4$ $\mathrm{mmHg}[95 \% \mathrm{CI}-19.79,-19.03])$. BP reductions from baseline to week 13 and the study endpoint were greater with the higher dose of Aml/Val (10/160 mg) (Fig. 2).

Reductions in BP from baseline were observed across all the subgroups based on age, sex, BMI, diabetes, and ISH (Table 2). Generally similar reductions were seen regardless of sex and in diverse patient subgroups, such as the older patients (aged $\geq 65$ years), obese patients (BMI $\geq 30$ $\mathrm{kg} / \mathrm{m}^{2}$ ), or patients with diabetes. BP reductions were dependent on the level of baseline SBP, with the greatest reductions observed in patients with baseline $\mathrm{SBP} \geq 180$ $\mathrm{mmHg}$ (Table 2).

\subsubsection{BP Goals and BP Response Rates}

At the week 26 endpoint, the proportion of patients achieving the therapeutic BP goal was 49.3\%. SBP and DBP response was achieved by 91.1 and $91.4 \%$ of patients, respectively (Fig. 3). In addition, the proportion of patients who achieved SBP and DBP response in the 5/160 and 10/160 mg Aml/Val dosage categories was almost similar to the response rates achieved in the overall population (Fig. 3). The physicians rated the effectiveness of the antihypertensive therapy as 'good' or 'very good' for $85 \%$ of patients. 
Table 1 Patient demographics and baseline characteristics

\begin{tabular}{|c|c|}
\hline Variable & $\mathrm{Aml} / \mathrm{Val}(N=2566)$ \\
\hline Age, years & $52.6 \pm 10.31$ \\
\hline Age $\geq 65$ years, $n(\%)$ & $287(11.2)$ \\
\hline Sex, male, $n(\%)$ & $1563(60.9)$ \\
\hline Race, Caucasian, $n(\%)$ & $2370(92.4)$ \\
\hline $\mathrm{BMI} \geq 30 \mathrm{~kg} / \mathrm{m}^{2}, n(\%)$ & $1189(46.3)$ \\
\hline Diabetes mellitus, $n(\%)$ & $882(34.4)$ \\
\hline Essential hypertension, $n(\%)$ & 2504 (97.6) \\
\hline Duration of hypertension, years & $7.9 \pm 7.26$ \\
\hline Previous antihypertensive treatment, $n(\%)$ & $2025(78.9)$ \\
\hline Selective beta-blockers & $629(24.5)$ \\
\hline ACEIs & $533(20.8)$ \\
\hline Dihydropyridine derivatives & $405(15.8)$ \\
\hline Angiotensin II antagonists & $272(10.6)$ \\
\hline ACEIs and diuretics & $198(7.7)$ \\
\hline Angiotensin II antagonists and diuretics & $161(6.3)$ \\
\hline Selective beta-blocking agents and thiazides & $94(3.7)$ \\
\hline Thiazides (plain) & $58(2.3)$ \\
\hline \multicolumn{2}{|c|}{ Number of different antihypertensive drugs as prior treatment, $n(\%)$} \\
\hline 1 & $1322(51.5)$ \\
\hline 2 & $570(22.2)$ \\
\hline 3 & $112(4.4)$ \\
\hline$>3$ & $16(0.6)$ \\
\hline $\mathrm{msSBP}, \mathrm{mmHg}$ & $164.4 \pm 14.92$ \\
\hline $\mathrm{msDBP}, \mathrm{mmHg}$ & $100.5 \pm 8.63$ \\
\hline Concomitant antihypertensive treatment, $n(\%)$ & $662(25.8)$ \\
\hline Selective beta-blocking agents & $421(16.4)$ \\
\hline Selective beta-blocking agents and thiazides & $69(2.7)$ \\
\hline
\end{tabular}

Data are presented as mean $\pm \mathrm{SD}$, unless otherwise stated

ACEIs angiotensin II converting enzyme inhibitors, Aml/Val amlodipine/valsartan, BMI body mass index, $m s D B P$ mean sitting diastolic blood pressure, $m s S B P$ mean sitting systolic blood pressure, $S D$ standard deviation

\subsection{Safety}

A total of $322(12.5 \%)$ patients reported at least one AE during the study period. The most frequent AEs were peripheral edema (1.8\%), bronchitis (1.1\%), and gastritis $(0.8 \%)$ (Table 3$)$. The incidence of edema was $15.7 \%$ (402 patients) at baseline and $13.3 \%$ (329 patients) at the end of the study. There were two deaths reported during the study period, neither of which was considered to be related to the study drug by the investigators. A 66-year-old male patient died of heart failure on day 1 of study commencement and a 43-year-old female patient died from unknown causes on day 82. Serious AEs were experienced by 12 patients $(0.5 \%)$. Of the SAEs reported, two events, chest tightness on day 8 and renal failure on day 152, were suspected by the investigators to be related to the study drug. The most frequent SAEs were cardiac disorders, reported in five patients $(0.2 \%)$.
Discontinuations owing to AEs were reported in 10 patients $(0.4 \%)$ : peripheral edema in five patients $(0.2 \%)$ and acute myocardial infarction, edema, increased blood creatinine, renal failure, and flushing, in one patient each. Both treatment compliance and tolerability were rated by investigators as 'good' or 'very good' for $88 \%$ of patients.

\section{Discussion}

Our study showed that Aml/Val SPC in a real-life setting significantly reduced BP from baseline to the week 26 endpoint in patients with hypertension from Egypt. Dosedependent BP reductions were observed at weeks 13 and 26, with greater BP reductions correlating with higher baseline SBP at week 26. Almost half of all patients in the study reached the therapeutic BP goal, and the majority of the patients attained SBP and DBP responses. In diverse 

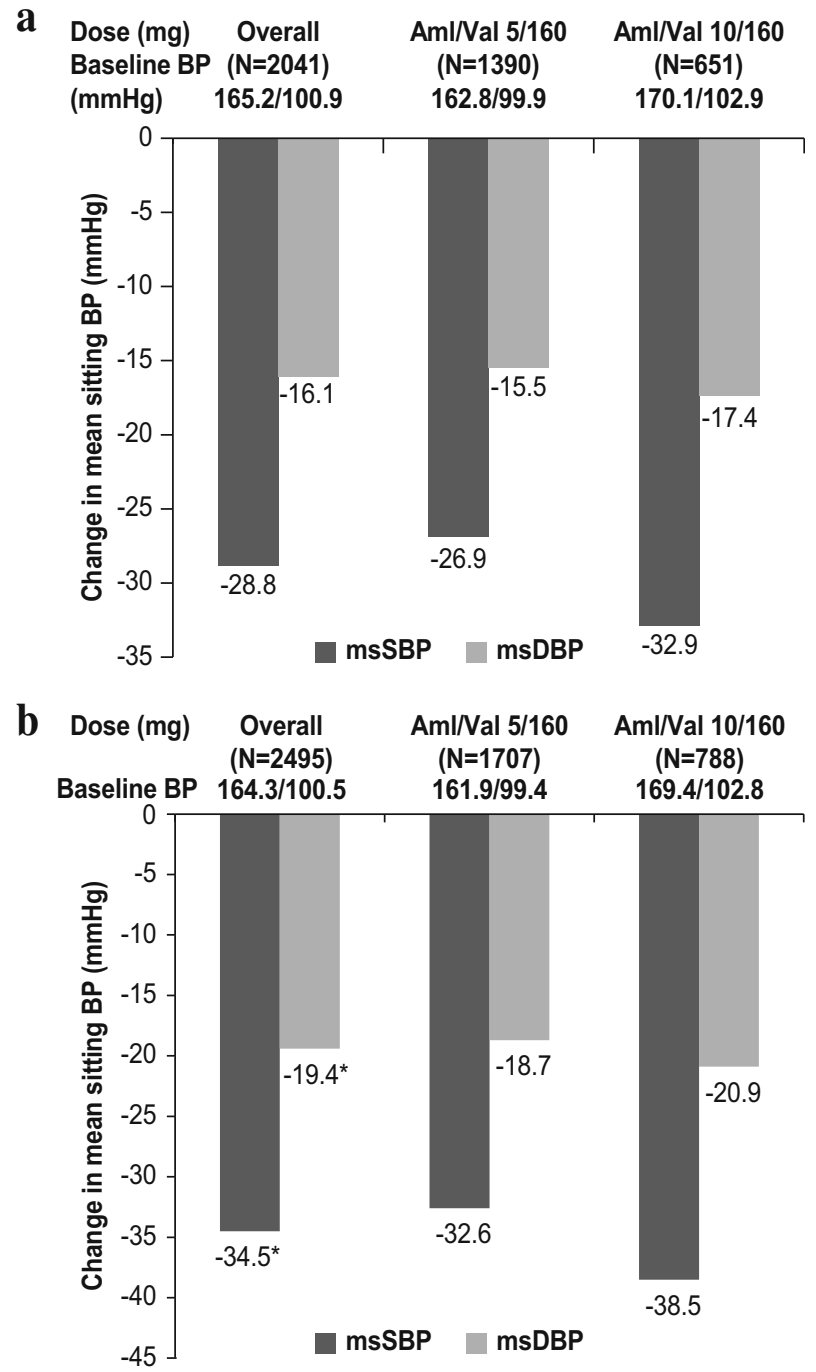

\begin{tabular}{|l|c|c|c|}
\hline $95 \% \mathrm{Cl}(\mathrm{LL}, \mathrm{UL})$ & Overall & Aml/Val 5/160 mg & AmI/Nal 10/160 mg \\
\hline msSBP & $-35.10,-33.85$ & $-33.33,-31.93$ & $-39.68,-37.26$ \\
\hline msDBP & $-19.79,-19.03$ & $-19.20,-18.27$ & $-21.55,-20.22$ \\
\hline
\end{tabular}

Fig. 2 a Mean change from baseline to week 13; b mean change from baseline to week 26 in $\mathrm{msSBP}$ and msDBP. Aml/Val amlodipine/valsartan, $B P$ blood pressure, $C I$ confidence interval, $L L$ lower limit, $m s D B P$ mean sitting diastolic blood pressure, $m s S B P$ mean sitting systolic blood pressure, $U L$ upper limit. ${ }^{*} p<0.0001$ vs. baseline

patient subgroups such as in older patients (aged $\geq 65$ years), obese patients (BMI $\geq 30 \mathrm{~kg} / \mathrm{m}^{2}$ ), or in patients with comorbid diabetes, similar and consistent reductions in $\mathrm{BP}$ were observed and were comparable to the reductions seen in the overall population. In addition, Aml/Val SPC was generally well tolerated in this patient population. Effectiveness, tolerability, and treatment compliance were rated by the physicians as 'good' and 'very good' for the majority of the patients.
The findings from this study compare well to previously reported real-life studies [14, 15], and seem to be generally consistent with the findings reported in randomized clinical trials evaluating the Aml/Val combination in patients with hypertension [13, 18-21]. In the present study, a dose-dependent decrease in msSBP was observed with $\mathrm{Aml} / \mathrm{Val}$, with reductions of -32.6 and $-38.5 \mathrm{mmHg}$ for the $5 / 160$ and 10/160-mg doses of Aml/Val, respectively. These results are consistent with previously reported 8-week randomized studies, wherein dose-dependent reductions in BP for the 5/160- and 10/160-mg doses of Aml/Val were observed [21]. The Exforge in Failure After Single Therapy (EX-FAST) study also showed an Aml/Val dose-dependent reduction in BP in patients with hypertension [18].

Our results are very similar to those obtained from other real-world studies with different populations, where significant SBP as well as DBP reductions of $33-36 \mathrm{mmHg}$ and $16-18 \mathrm{mmHg}$, respectively, with the Aml/Val freedose combination $(5 / 80,10 / 160 \mathrm{mg})$ and the $\mathrm{Aml} / \mathrm{Val} \mathrm{SPC}$ $(5 / 80,5 / 160$, or $10 / 160 \mathrm{mg})$ were observed $[14,15]$. These real-world studies also demonstrated dose-dependent, BPlowering effects and greater BP-lowering effects with increasing severity of baseline SBP. It is important to note that the baseline BP of the patient populations in both these studies (baseline BP ranging from 163.1 to 165.0/96.2 to $99.3 \mathrm{mmHg}$ ) is very similar to that of the current study's patient cohort (baseline BP, 164.3/100.5 mmHg). Similar to the results of the current study, data from a recent 12-week real-life study conducted in Egyptian patients with hypertension reported that $\mathrm{Aml} / \mathrm{Val} \mathrm{SPC}$ resulted in significant mean BP reductions of $-39.4 /-21.7 \mathrm{mmHg}$ $(p<0.001)$ at the end of the study (baseline BP, 171.5/ $103.4 \mathrm{mmHg}$ ). In addition, dose-dependent BP lowering was observed with Aml/Val doses of 5/160 and 10/160 mg, with a comparable BP reduction of $-34.6 /-19.2 \mathrm{mmHg}$ with 5/160 mg Aml/Val [22]. BP reductions observed in this study are greater than the BP-lowering effect reported by the EXCITE study in patients with hypertension from Pakistan (-24.5/-12.7 mmHg; baseline BP: 153.4/91.1 $\mathrm{mmHg}$ ), and the overall EXCITE study results $(-31.0 /$ $-16.6 \mathrm{mmHg}$; baseline BP: $160.9 / 97.1 \mathrm{mmHg}$ ) [17, 23]. The differences in BP reductions between the current study and the data of EXCITE studies from other countries might be owing to differences in the study population as well as in the baseline BP. In this study, BP reductions observed were consistent across patient subgroups, regardless of age, diabetic status, sex, and BMI, and were generally similar to previously reported controlled efficacy studies conducted in various subgroups studied [19, 20, 24].

Achievement of the therapeutic BP goal continues to remain a challenge for most patients receiving antihypertensive therapy [25]. In this study, more than $90 \%$ of all patients achieved the BP response with Aml/Val SPC 
Table 2 Mean sitting BP reduction $(\mathrm{mmHg})$ from baseline to week 26 by subgroups
Fig. 3 Proportion of patients who achieved therapeutic blood pressure goal and response at week 26. Aml/Val amlodipine/valsartan, $D B P$ diastolic blood pressure, $S B P$ systolic blood pressure

\begin{tabular}{|c|c|c|c|c|}
\hline \multirow[t]{2}{*}{ Subgroups } & \multirow[t]{2}{*}{$N$} & \multicolumn{3}{|l|}{$\mathrm{Aml} / \mathrm{Val}$} \\
\hline & & Baseline $\mathrm{msBP}$ & msSBP & $\mathrm{msDBP}$ \\
\hline \multicolumn{5}{|l|}{ Age, years } \\
\hline$<65$ & 2209 & $163.9 / 100.7$ & $-34.3(-34.95,-33.65)$ & $-19.6(-20.01,-19.20)$ \\
\hline$\geq 65$ & 275 & 168.0/99.1 & $-36.3(-38.50,-34.17)$ & $-18.0(-19.21,-16.82)$ \\
\hline \multicolumn{5}{|l|}{ Sex } \\
\hline Male & 1526 & $163.8 / 100.3$ & $-33.9(-34.67,-33.06)$ & $-18.8(-19.34,-18.35)$ \\
\hline Female & 968 & $165.0 / 100.9$ & $-35.4(-36.38,-34.42)$ & $-20.3(-20.90,-19.71)$ \\
\hline \multicolumn{5}{|l|}{ BMI, $\mathrm{kg} / \mathrm{m}^{2}$} \\
\hline$<30$ & 1214 & $163.4 / 99.5$ & $-34.0(-34.82,-33.09)$ & $-18.5(-19.03,-17.94)$ \\
\hline$\geq 30$ & 1159 & $164.9 / 101.5$ & $-34.5(-35.45,-33.58)$ & $-20.2(-20.76,-19.64)$ \\
\hline \multicolumn{5}{|c|}{ Diabetes mellitus } \\
\hline Yes & 862 & $164.4 / 100.2$ & $-33.8(-34.92,-32.64)$ & $-19.3(-19.95,-18.62)$ \\
\hline No & 1633 & $164.2 / 100.6$ & $-34.8(-35.58,-34.10)$ & $-19.5(-19.95,-19.01)$ \\
\hline \multicolumn{5}{|c|}{ Baseline SBP, mmHg } \\
\hline$<140$ & 41 & $127.7 / 89.0$ & $-3.7(-6.82,-0.60)$ & $-12.0(-15.14,-8.96)$ \\
\hline 140 to $<160$ & 607 & $148.8 / 97.6$ & $-22.1(-22.86,-21.28)$ & $-16.8(-17.56,-16.06)$ \\
\hline 160 to $<180$ & 1392 & $164.5 / 100.7$ & $-34.1(-34.66,-33.62)$ & $-19.4(-19.91,-18.94)$ \\
\hline$\geq 180$ & 455 & $187.5 / 104.9$ & $-54.8(-56.22,-53.41)$ & $-23.5(-24.44,-22.56)$ \\
\hline \multicolumn{5}{|c|}{ ISH $(\mathrm{SBP} \geq 140 \mathrm{mmHg}$ and $\mathrm{DBP}<90 \mathrm{mmHg}$ ) } \\
\hline Yes & 90 & $158.1 / 80.6$ & $-27.8(-30.67,-24.98)$ & $-3.1(-4.75,-1.47)$ \\
\hline No & 2405 & $164.5 / 101.3$ & $-34.7(-35.36,-34.09)$ & $-20.0(-20.39,-19.65)$ \\
\hline
\end{tabular}

Data are mean (95\% confidence intervals)

$\mathrm{Aml} / \mathrm{Val}$ amlodipine/valsartan, $B M I$ body mass index, $D B P$ diastolic blood pressure, $I S H$ isolated systolic hypertension, $m s B P$ mean sitting blood pressure, $m s D B P$ mean sitting diastolic blood pressure, $m s S B P$ mean sitting systolic blood pressure, $S B P$ systolic blood pressure

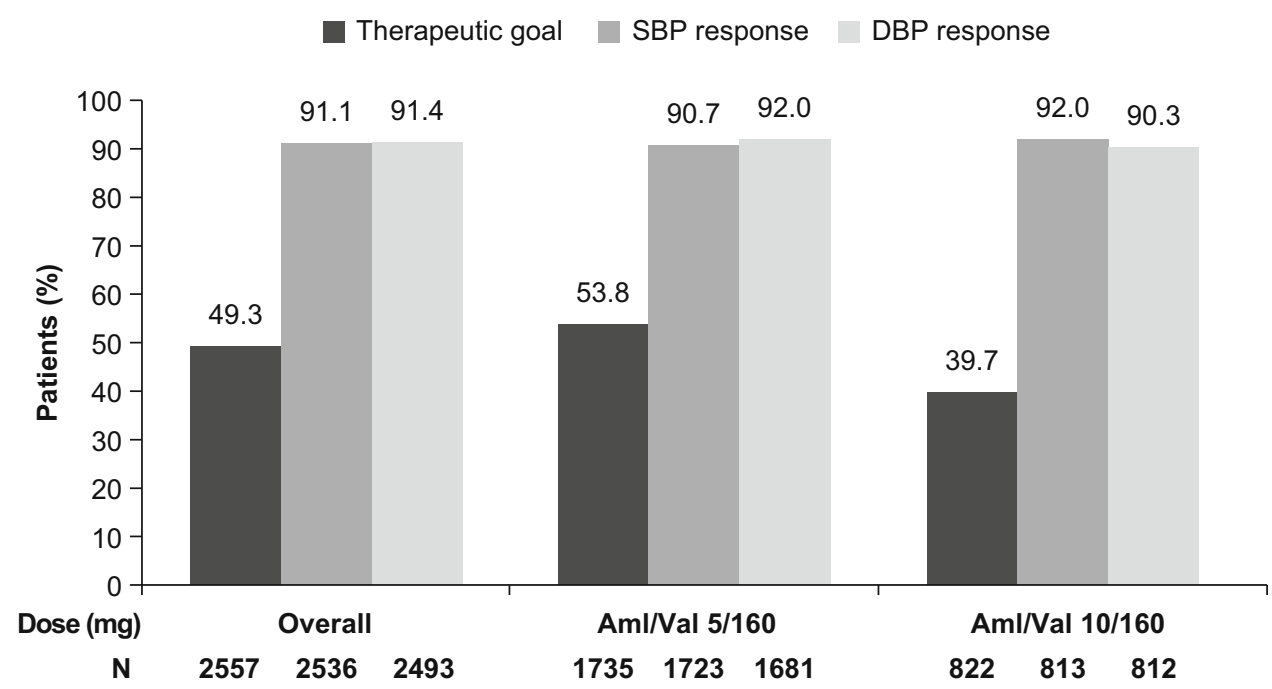

treatment, and BP control was achieved in almost $50 \%$ of patients. Of note, this study included diverse patient subgroups (older patients, $11.2 \%$; obese patients, $46.3 \%$; and patients with diabetes, $34.4 \%$ ), in whom achieving the target BP goals and responses is difficult.
Lack of adherence to antihypertensive therapy is a potential reason for patients not achieving BP goals. Previous findings on the use of Aml/Val SPC in a real-world setting showed better treatment adherence and persistence, and lower healthcare costs and utilization, relative to free 
Table 3 Most frequently $(\geq 0.5 \%)$ reported AEs (regardless of relationship to the study drug)

\begin{tabular}{ll}
\hline AEs & Aml/Val $(N=2566) n(\%)$ \\
\hline Patients with $\geq 1$ AEs & $322(12.5)$ \\
Edema peripheral & $45(1.8)$ \\
Bronchitis & $28(1.1)$ \\
Gastritis & $20(0.8)$ \\
Lower respiratory tract infection & $19(0.7)$ \\
Edema & $17(0.7)$ \\
Headache & $17(0.7)$ \\
Nausea & $14(0.5)$ \\
Urinary tract infection & $14(0.5)$ \\
Nasopharyngitis & $13(0.5)$ \\
Cough & $12(0.5)$
\end{tabular}

AEs adverse events, Aml/Val amlodipine/valsartan

combinations of ARB plus CCB among patients with hypertension [26]. In our study, the treatment compliance was assessed by physicians to be 'good' or 'very good' for $88 \%$ of patients.

The safety profile of the Aml/Val combination in this real-life study was consistent with previously reported randomized and real-life studies on Aml/Val $[13,14,18,21,22]$. Edema is a well-documented $\mathrm{AE}$ of CCBs that is commonly reported with amlodipine. The incidence of edema was less in this study, and these results are in agreement with other real life studies that have reported lowering of edema upon combining $\mathrm{CCBs}$ with ACEIs or ARBs $[14,15]$.

This study has inherent limitations with respect to interpretation of its results as it is an observational, openlabel, non-randomized, non-controlled study by design, and caution needs to be employed while deriving conclusions. The findings of this study are restricted to the cohort investigated here and cannot be extended to other patient populations. The real-life setting of our study does not permit us to make decisive conclusions on comparative efficacy and safety of the Aml/Val SPC. Another limitation of the study is that the addition of Aml/Val SPC to other antihypertensive therapies might have contributed to an increase in the treatment efficacy and this influence has not been analyzed. An additional limitation is the use of subjective evaluation scales for the physicians' assessment of effectiveness, tolerability, and treatment compliance in this study. However, owing to its strength as an observational study by design with a large sample size, data could be obtained from diverse patient populations with hypertension, thereby making the results of this study more relevant to clinical practice in a real-life setting.

\section{Conclusion}

In this observational study conducted in patients with hypertension from Egypt, Aml/Val SPC provided statistically significant reductions in BP from baseline to week 26 . In addition, Aml/Val was generally well tolerated. Thus, the results of the EXCITE study provide evidence from a real-world setting that Aml/Val SPC is effective and well tolerated in patients with hypertension from Egypt.

Acknowledgments Medical writing and editorial assistance for manuscript preparation was provided by Parvathy Ramakrishnan (Novartis Healthcare Private Ltd, Hyderabad, India). Statistical analysis was performed by Biometrical Practice AG, Basel, Switzerland.

Author contributions Samir H. Assaad-Khalil and Nashwa Nashaat were involved in the concept and design of the study. Both the authors were involved in data collection, analysis, and/or interpretation of the results. As Nashwa Nashaat is no longer an employee of Novartis, Samir H. Assaad-Khalil was responsible for critical revision, and approval of the article.

\section{Compliance with Ethical Standards}

Ethical approval The study protocol was reviewed and approved by an institutional review board/independent ethics committee/research ethics board before the start of the study. All procedures performed in studies involving human participants were in accordance with the ethical standards of the institutional and/or national research committee and with the 1964 Helsinki Declaration and its later amendments or comparable ethical standards.

Informed consent Informed consent was obtained from all individual participants included in the study.

Conflict of interest Samir H. Assaad-Khalil has received investigator fees related to the conduct of the EXCITE study from Novartis and its affiliates. Nashwa Nashaat was an employee of Novartis Pharma S.A.E at the time of study completion and manuscript preparation.

Funding The EXCITE study was funded by Novartis Pharma AG, Basel, Switzerland. This work was supported by Novartis Pharma, Cairo, Egypt. Medical writing and editorial assistance for manuscript preparation was funded by Novartis Pharma, Cairo, Egypt.

Open Access This article is distributed under the terms of the Creative Commons Attribution-NonCommercial 4.0 International License (http://creativecommons.org/licenses/by-nc/4.0/), which permits any noncommercial use, distribution, and reproduction in any medium, provided you give appropriate credit to the original author(s) and the source, provide a link to the Creative Commons license, and indicate if changes were made.

\section{References}

1. Kearney PM, Whelton M, Reynolds K, Muntner P, Whelton PK, He J. Global burden of hypertension: analysis of worldwide data. Lancet. 2005;365:217-23. 
2. Lim SS, Vos T, Flaxman AD, Danaei G, Shibuya K, Adair-Rohani $\mathrm{H}$, et al. A comparative risk assessment of burden of disease and injury attributable to 67 risk factors and risk factor clusters in 21 regions, 1990-2010: a systematic analysis for the Global Burden of Disease Study 2010. Lancet. 2012;380:2224-60.

3. El-Zanaty F, Way A. Egypt Demographic and Health Survey 2008. Cairo: Ministry of Health, El-Zanaty and Associates, and Macro International; 2009. http://dhsprogram.com/pubs/pdf/ FR220/FR220.pdf. Accessed 19 Nov 2013.

4. Arafa NAS, Ez-Elarab HS. Epidemiology of prehypertension and hypertension among Egyptian adults. Egypt J Commun Med. 2011;29:1-18.

5. Wolf-Maier K, Cooper RS, Kramer H, Banegas JR, Giampaoli S, Joffres MR, et al. Hypertension treatment and control in five European countries, Canada, and the United States. Hypertension. 2004;43:10-7.

6. Ibrahim MM, Damasceno A. Hypertension in developing countries. Lancet. 2012;380:611-9.

7. Taylor AA. Combination drug treatment of hypertension: have we come full circle? Curr Cardiol Rep. 2004;6:421-6.

8. Ibrahim MM. The Egyptian Hypertension Society: Egyptian hypertension guidelines: 2013. http://ehs-egypt.net/index.php?option= com_downloads\&task=view\&id=35\&Itemid $=64$. Accessed 20 Jan 2014.

9. Mancia G, Fagard R, Narkiewicz K, Redon J, Zanchetti A, Bohm $\mathrm{M}$, et al. $2013 \mathrm{ESH} / \mathrm{ESC}$ guidelines for the management of arterial hypertension: the Task Force for the Management of Arterial Hypertension of the European Society of Hypertension (ESH) and of the European Society of Cardiology (ESC). J Hypertens. 2013;31:1281-357.

10. Mallat SG, Itani HS, Tanios BY. Current perspectives on combination therapy in the management of hypertension. Integr Blood Press Control. 2013;6:69-78.

11. Calhoun DA, Crikelair NA, Yen J, Glazer RD. Amlodipine/valsartan/hydrochlorothiazide triple combination therapy in moderate/severe hypertension: secondary analyses evaluating efficacy and safety. Adv Ther. 2009;26:1012-23.

12. Lins R, Aerts A, Coen N, Hermans C, MacDonald K, Brie H, et al. Effectiveness of amlodipine-valsartan single-pill combinations: hierarchical modeling of blood pressure and total cardiovascular disease risk outcomes (the EXCELLENT study). Ann Pharmacother. 2011;45:727-39.

13. Smith TR, Philipp T, Vaisse B, Bakris GL, Wernsing M, Yen J, et al. Amlodipine and valsartan combined and as monotherapy in stage 2, elderly, and black hypertensive patients: subgroup analyses of 2 randomized, placebo-controlled studies. J Clin Hypertens (Greenwich). 2007;9:355-64.

14. Chazova IE, Dongre N, Vigdorchik AV. Real-life safety and effectiveness of amlodipine/valsartan combination in the treatment of hypertension. Adv Ther. 2011;28:134-49.

15. Karpov Y, Dongre N, Vigdorchik A, Sastravaha K. Amlodipine/valsartan single-pill combination: a prospective, observational evaluation of the real-life safety and effectiveness in the routine treatment of hypertension. Adv Ther. 2012;29:134-47.

16. Ware JH, Hamel MB. Pragmatic trials: guides to better patient care? N Engl J Med. 2011;364:1685-7.

17. Sison J, Assaad-Khalil SH, Najem R, Kitchlew AR, Cho B, Ueng $\mathrm{KC}$, et al. Real-world clinical experience of amlodipine/valsartan and amlodipine/valsartan/hydrochlorothiazide in hypertension: the EXCITE study. Curr Med Res Opin. 2014;30:1937-45.

18. Allemann Y, Fraile B, Lambert M, Barbier M, Ferber P, Izzo JL Jr. Efficacy of the combination of amlodipine and valsartan in patients with hypertension uncontrolled with previous monotherapy: the Exforge in Failure after Single Therapy (EXFAST) study. J Clin Hypertens (Greenwich). 2008;10:185-94.

19. Destro M, Luckow A, Samson M, Kandra A, Brunel P. Efficacy and safety of amlodipine/valsartan compared with amlodipine monotherapy in patients with stage 2 hypertension: a randomized, double-blind, multicenter study: the EX-EFFeCTS Study. J Am Soc Hypertens. 2008;2:294-302.

20. Flack JM, Calhoun DA, Satlin L, Barbier M, Hilkert R, Brunel P. Efficacy and safety of initial combination therapy with amlodipine/valsartan compared with amlodipine monotherapy in black patients with stage 2 hypertension: the EX-STAND study. J Hum Hypertens. 2009;23:479-89.

21. Philipp T, Smith TR, Glazer R, Wernsing M, Yen J, Jin J, et al. Two multicenter, 8-week, randomized, double-blind, placebocontrolled, parallel-group studies evaluating the efficacy and tolerability of amlodipine and valsartan in combination and as monotherapy in adult patients with mild to moderate essential hypertension. Clin Ther. 2007;29:563-80.

22. Kafrawy NE, Rashwan M, Lion K, Khedr K, Nashaat N. Effectiveness and tolerability of fixed dose combination of amlodipine/valsartan in treatment of hypertension in the real-life setting among Egyptian patients. Egyptian Heart J. 2014;66:30-5.

23. Khan W, Moin N, Iktidar S, Sakrani J, Abid R, Afzal J, et al. Real-life effectiveness, safety, and tolerability of amlodipine/valsartan or amlodipine/valsartan/hydrochlorothiazide singlepill combination in patients with hypertension from Pakistan. Ther Adv Cardiovasc Dis. 2014;8:45-55.

24. Calhoun DA, Lacourciere Y, Crikelair N, Jia Y, Glazer RD. Effects of demographics on the antihypertensive efficacy of triple therapy with amlodipine, valsartan, and hydrochlorothiazide for moderate to severe hypertension. Curr Med Res Opin. 2013;29:901-10.

25. Pereira M, Lunet N, Azevedo A, Barros H. Differences in prevalence, awareness, treatment and control of hypertension between developing and developed countries. J Hypertens. 2009;27:963-75.

26. Baser O, Andrews LM, Wang L, Xie L. Comparison of realworld adherence, healthcare resource utilization and costs for newly initiated valsartan/amlodipine single-pill combination versus angiotensin receptor blocker/calcium channel blocker freecombination therapy. J Med Econ. 2011;14:576-83. 